Information gathered from official sources shows that the damage caused by locusts during the present outbreak (the period 1927-31) can be estimated, in round numbers, as exceoding $\mathfrak{1} 6,000,000$, while about $£ 1,000,000$ has been spent on control measures. The whole course of this outbreak clearly indicates how close is the dependence of the locust situation in any one territory on the general incidence of the pest over wide areas. This interdependence shows that it is almost futile to control locusts in a fow isolated districts. There is an urgent need for concentrating on investigations into the original breeding grounds of each locust species. The discovery of such areas would opon up the possibility of each species being dealt with under relatively localised conditions before it is ablo to spread and bocome diffused.

The events of the past two years all omphasise the urgency of discovering the specific factors that result in locust invasions in order that a far-reaching policy for the prevention, or at least the reduction of future outbreaks, may be devised. The Committee has drawn up a comprehensive programme of work that it recommends to bo carried out in 1932-33 and undertaken through the Imperial Institute of Entornology. At the headquartors of the Institute it is advised that the collection, study and analysis of availablo information on the problems involved should be continued and extended. The work also includes the task of transferring all records, both old and new, of locust migrations and breeding to maps covering dofined periods. Such maps should prove invaluable for tracing the courses of all known invasions and in serving as the basis for studies connected with them. Furthermore, as the Institute is acting as tho recognised international clearing. house for all information dealing with anti-locust investigation, in this way it is in a position to assist all countries directly affected by invasions. The collec. tion of specimens from swarms appearing in different lands, and at diverse times, is also being undertakon and their availability at the Institute will provide essential material for biometrical and other studies of the phase problem.

The field campaign, drawn up by the Committee, covers the investigation of the lifo-cycles of the locust species already mentioned; studies of their swarming and transitional phases; the correlation of locust activities with meteorological data and the testing of control measures. Theso aspects of the work will continue under the direction of the Chief Locust Investigator, Mr H. B. Johnston.

Tho co-operation of the governments of all countries affected by locust invasions is a matter of prime importance. It is now recognised that investi. gations of the character planned require to be international if the basic problems concerned are to be fully solved. The Committee acknowledges tho value of the co-operation alroady afforded by the French and Italian Governments, and by the administrations of British colonies and territories, but is anxious to develop mutual effort and the pooling of information on a much wider scale. Recommendations are consequently made that the Economic Advisory Council should invite the Secretary of State for Foreign Affairs to communicate copies of the present report with an expression of hope of co-operation, in the work now planned, of govern. ments that were not represented at the Rome conference on locust control in 1931 .

In the matter of finance, the recommendations of the Committec are on a very modest scale considering the importance of the schemes involved. The 1932-33 programme, as estimated, can be carried out at a cost of $£ 3,800$, of which $£ 395$ represents capital expendituro on tents, apparatus, etc., and $£ 3,405$ is recurrent oxpenditure mainly for salaries, wages and travelling charges. It is to be hoped that the campaign now taking shape will be allowed to develop so fully as possible, in view of the magnitude of the losses sustained through locust invasions in so many areas of the British Empire and indoed throughout the world.
A. D. ImMs.

\title{
The Rubber Industry of Malaya
}

A SERIES of memoranda with an introduction by Dr. H. A. Tempany which have recently been issued in Malaya deal with the position of the Rubber Resuarch Institute of Malaya and indicate that four distinct proposals for the future are before the Board. The retrenchment momorandum put forward by the executive committee estimates 350,000 dollars as tho sum on which the Institute's activities can be main. tained. This involves a reduction in expenditure of 183,000 dollars and at a special meeting of the Board of the Institute held on June 28, the recommendations of the executive committee were adopted with minor modifications.

The propasal of the Hon. B. J. R. Barton that the whole of the work of the Institute should be amalgamated with the Department of Agriculture was prompted by the belief that, while the retrenchment proposals did not go far enough to bring relief to subsoribers in any appreciable reduction in payment of cess, they would accentuate a feeling of discontent among tho staff of the Institute and that the organisation would not represent the best possible in the interests of the Industry. Mr. Barton stressed the advantages of the Department of Agriculture and while the retrenchment proposals may involve curtailing the advisory work, the activities of the
Institute can scarcely be maintained at more than a semblance of their present efficiency. The representatives of the Malaya Fstate Owners Association urged that the situation should be investigated by an indopendent body, but this proposal was also negatived.

The proposals adoptod by the Board, after accepting the view that 350,000 dollars represents the minimum upon which the activities of the Institute can be effectively muintained and the maximum which can be at present expected from the export cess levied on rubber, since the area of untapped rubber which escapes all contributions is expected to increase, provide for retrenchment by reduction in salaries, in the personnel and on allowances for cess, etc., on duty. In addition to a reduction of 5 per cent already imposed, a further reduction of 20 per cent on all salaries is now contemplated. With regard to personnel, the research servicos are graded in the order of importance, chemical, botanical, pathological, soils, field; and restriction of activity by reduction of personnel is advocated to fall with increasing incidence in the descending order shown above. On account of the increasing importance of latex, it is recommended that reduction in the chemical and pathological divisions where research on latex

No. 3292, VoL. 130] 
is principally carried out should be a minimum. The heads of divisions presented alternative proposals which also were not accepted. These proposals were backed by a strong plea that they were the outcome of careful thought by those who had exceptional opportunities of studying the working of the Institute and the needs of the industry. They recommend a complete reorganisation of the personnel and work of the Institute on two main lines : (i) work on the product-chemical; (ii) work on the tree-botanical, including agricultural and both research and advisory work. They envisage four senior scientific officers and one administrative officer working as an executive cabinet under a director, preferably someone quite free from outside affiliations and selected mainly for administrative ability and experience. Such a scheme, if staffed with officers capable of working in absolute harmony, should develop the team spirit essential to success. A selection and a list of temporary salaries were included with these proposals.

In view of the growing recognition of the importance of Imperial research on Empire products, it is disappointing to learn of this serious threat to rubber research and the uneasiness with which scientific workers and others regard the situation will not be diminished by the Board's dismissal of the alternative scheme and proposals put forward by the scientific and technical heads of divisions. The reductions in salary and personnel adopted by the Board appear likely to have an untoward effect on the recruitment for Imperial services abroad generally. In view of the comparatively early age of retirement in such services and the difficulty frequently experienced in securing an appointment on return to Great Britain, such drastic reductions in salaries will deter many promising scientific officers of high ability from coming forward for service abroad.

\section{Ultra-short Wave Technique in Radio Communication}

$A^{T}$ the International Congress of Electricity held $A$ in Paris in July last, some twenty-six papers were read before Section 9 dealing with various aspects of radio engineering, ranging from commercial telephonic communication to the study of the electrical properties of the upper atmosphere. Among these papers, two are of particular interest in connexion with the progress of ultra-short wave technique.

The first of these, by I. E. Mouromtseff and H. V. Noble, describes a new type of ultra-short wave oscillator. This consists of a special three electrode valve in which the cylindrical anode and spiral grid form part of a concentric transmission line, which itself replaces the tuned circuit normally associated with an oscillating triode. For cylindrical conductors the diameters of which are of constant ratio, the inductunce and capacity of the line will satisfy the condition of uniformity of distribution, and when the necessary supply voltages are connected to the electrodes at suitable points oscillations will be set up on the line at a wave-length equal to twice the length of the line. These oscillations take the form of stationary waves giving rise to no external field or radiation, but a suitable open or closed circuit may be coupled to the line, in order to make use of the high frequency power. A large water-cooled transmitting valve constructed on this principle has been made to generate up to 16 kilowatts at wave-lengths of 3 and 5 metres, with an efficiency of from 20 to 40 per cent.

The use of this principle would appear to overcome some of the difficulties of making high-power valves for short wave-lengths, which arise from the necessity of reducing inter-electrode capacity in valve oscillators using one of the ordinary circuit arrangements. Since the reading of the paper in Paris, a more complete account of this work has been published in the Proceedings of the Institute of Radio Engineers for August 1932.

In the second paper, I. E. Mouromtseff and G. R. Kilgore give a description of some experiments on a magneto-static oscillator for the production of oscillations at wave-lengths of $50 \mathrm{~cm}$. or less. The special valves employed are similar to the magnetron type, comprising a cylindrical anode, split longitudinally into two parts, and containing a straight axial filament. This valve is placed in a suitable coil supplying a constant magnetic field in the direction of the axis. The two halves of the anode are connected to two parallel wires forming a Lecher wire system which can be adjusted to resonate at the desired wavelength. Yagi and Okabe had previously remarked that, in the ordinary magnetron, when the conditions were such that the electrons passed very close to the anode without touching it, weak oscillations of a very high frequency were to be observed.

The present researches show that the intensity of these oscillations can be enormously increased if the direction of the magnetic field is altered by a small angle from the axis of the valve electrodes. Graphs accompanying the paper referred to above, show that the oscillations attain a maximum intensity for angles between $2^{\circ}$ and $10^{\circ}$, depending upon the dimensions and operating conditions of the valve. Examples are quoted in the paper of valves capable of producing oscillations of appreciable intensity at wave-lengths of $22-55 \mathrm{~cm}$.

R. L. S.-R.

\section{University and Educational Intelligence}

Brrmingham.-The Executive Board of the Birm. ingham Hospitals Centre, of which Sir Charles Grant Robertson is chairman, has decided to proceed immediately with the provision of the new hospital at Edgbaston on the site of 100 acres adjoining the University given by Messrs. Cadbury Brothers. The first instalment is to consist of 500 beds. This scheme (which has been suspended for many months in consequence of the national financial stringency) is of vital importance to the University, the Medical School of which is to be housed in buildings forming part of the hospitals centre. It has been disclosed that a contribution of $£ 52,000$, hitherto anonymous, was made by Sir William Morris (of Morris Motors Ltd.) on the understanding that the work should be begun by January 1, 1933. A donation of $£ 100,000$ was made by Mr. Harry Vincent, treasurer of the fund, and another contribution, by an anonymous donor, of $£ 50,000$ has been received. The total cost of buildings and equipment is estimated at above $£ 718,000$, of which more than $£ 647,000$ has already been contributed or promised.

Cambridge.-The General Board has recommended that vertebrate zoology be added to the list of subdepartments in the Department of Zoology, with the reader in vertebrate zoology as director of the sub-

No. 3292, VoL. 130] 